\title{
Spiritual Awareness in the Healthcare Workplace
}

\author{
Reverend Anthony J. De Conciliis, CSC, PhD \\ The Institute of Medicine, Education, and Spirituality at Ochsner, Ochsner Clinic Foundation, New Orleans, LA
}

\section{TO THE EDITOR}

An increasing number of research articles and books support a closer relationship between business practice, ethics, and spiritual values. ${ }^{1-4}$ The literature calls upon all leaders to devote attention to spiritual values and their corresponding virtues. However, like many modern industries, healthcare is subject to extraordinary change and challenge. Consequently, healthcare leaders are forced to concentrate more and more on empirical metrics, such as the amount of time professionals spend with each patient. Because of this focus on metrics, the quality of the patient-provider interaction can be drastically affected. The patient and the provider have less time together and are less able to attend to the internal life that is so important to the success of the healing process. ${ }^{5}$

Throughout the healthcare workplace, increased expectations on all staff place pressure on work-life balance. The result can be burnout, a major issue that negatively affects employee connectedness, meaning, purpose, nurturance, and hope connected with one's vocation and workplace.

To offset these pressures, healthcare leaders must seek to develop an integrated culture-mind, body, and spiritwhere attention is given to the spiritual culture of the workplace. In the literature, this integrative practice is known as workplace spirit or spirituality. ${ }^{6}$ But much work remains to be done. Gull and Doh report that "Despite an extensive set of critiques and criticisms offered by scholars and practitioners, most modern organizations remain devoid of a spiritual foundation and deny their employees the opportunity for spiritual expression through their work."7

Dr Alton Ochsner, one of the founders of the Ochsner Health System, recognized the importance of values and virtues in the workplace and expressed these principles in his creed. One of his principles was simply to "Be honest with others and with yourself." Dr Ochsner believed that when the values of a person's spirit are acknowledged, the result is reciprocal caring and healing. The Institute of Medicine, Education, and Spirituality at Ochsner supports the development of workplace spirit in partial fulfillment of the Ochsner mission and values as envisioned by the institution's founders.

\section{REFERENCES}

1. Fairholm GW. Real Leadership: How Spiritual Values Give Leadership Meaning. Santa Barbara, CA: Praeger; 2011.

2. Cavanaugh GF, Bandsuch MR. Virtue as a benchmark for spirituality in business. J Bus Ethics. Jun 2002;38(1-2):109-117. doi: 10.1023/A:1015721029457.

3. Jurkiewicz $\mathrm{CL}$, Giacalone RA. A values framework for measuring the impact of workplace spirituality on organizational performance. J Bus Ethics. Jan 2004;49(2):129-142. doi: 10.1023/ B:BUSI.0000015843.22195.b9.

4. Sheep ML. Nurturing the whole person: the ethics of workplace spirituality in a society of organizations. J Bus Ethics. Jul 2006;66 (4):357-375. doi: 10.1007/s10551-006-0014-5.

5. Greider W. The Soul of Capitalism: Opening Paths to a Moral Economy. New York, NY: Simon \& Schuster; 2003.

6. Kolodinsky RW, Giacalone RA, Jurkiewicz CL. Workplace values and outcomes: exploring personal, organizational, and interactive workplace spirituality. J Bus Ethics. Aug 2008;81 (2):465-480. doi: 10.1007/s10551-007-9507-0.

7. Gull GA, Doh J. The "transmutation" of the organization: toward a more spiritual workplace. J Manag Inquiry. Jun 2004;13 (2):128-139. doi: 10.1177/1056492604265218. 